\title{
New alignments for the digital age: insights into connected learning
}

\author{
Sarah Prestridge ${ }^{1}$ (D) Michele Jacobsen ${ }^{2} \cdot$ Sadaqat Mulla $^{3} \cdot$ Sandra Gudiño Paredes $^{4}$. \\ Amina Charania ${ }^{3}$
}

Accepted: 29 January 2021 / Published online: 9 February 2021

(c) Crown 2021

\begin{abstract}
In an age of ready access to people, online spaces and information, canonized formal knowledge acquisition is being disrupted. The emergence of socially constructed knowledge based on connected learning is democratising education and re-framing how formal and informal learning is considered. What we currently understand connected learning to be is limited to a combination of individual interests, networked and interdependent relationships with interconnected experiences that transcend temporal, spatial and cultural boundaries. Connected learning does not reduce learning to a phenomenon that takes place exclusively in the restricted spaces of formal education, neither does it focus exclusively on the online learning phenomenon. As such our conceptualisation of connected learning needs to deepen to effectively be able to rationalise how people learn in a digital age. This paper begins to unlock concepts and ideas associated with connected learning using current examples, setting out to build a theoretical model which begins to frame the complexities of conceptualized self-driven global learning interactions.
\end{abstract}

Keywords Connected learning $\cdot$ Networked learning $\cdot$ Social media $\cdot$ Digital age

Sarah Prestridge

S.prestridge@griffith.edu.au

Michele Jacobsen

dmjacobs@ucalgary.ca

Sadaqat Mulla

sadaqat.mulla@tiss.edu

Sandra Gudiño Paredes

sandra.gudino@tec.mx

Amina Charania

amina.charania@tiss.edu

1 Griffith University, Brisbane, Australia

2 University of Calgary, Calgary, Canada

3 Tata Trusts, Mumbai, India

4 Tecnológico de Monterrey, Monterrey, Mexico 


\section{Introduction}

Connected learning is a new alignment for the digital age and therefore, it is important to examine its complexities. Connected learning environments are generally characterized by a sense of shared purpose, a focus on knowledge production, and networked infrastructures. Models that reflect this phenomenon include learning communities, communities of practice, teacher networks, among others, all of which provide ways of bridging formal and informal learning environments and bringing communities together. A strong nuance about connected learning is that it is self-driven rather than externally determined, meaning that a quasi environment may be 'created' but the learning connections are individually generated. Issues of inequity in access to new media have been noted as well as the unbounded network of learning pathways due to individualised needs (Ito et al. 2013).

Connected learning can be realized (simply) when a person is able to pursue a personal interest or passion with the support of another (friends, caring adults, knowledgeable others) and is in turn able to link this learning and interest to academic achievement, career success and or civic engagement (Ito et al. 2013). Its purpose is to enrich the co-creation of foundational literacy and knowledge, while also diversifying and multiplying pathways to opportunity and meaningful participation in society. Therefore, connected learning does not reduce learning to a phenomenon that takes place exclusively in the restricted spaces of formal education neither does it focus exclusively within social media or the online learning phenomenon. Rather, it refers to any learning experience where people co-create and share artefacts meaningful to their community (centered production), which affords abundant resources accessible to all (openly networked) who share a common purpose (shared purpose). In this exploratory paper we examine three varied concepts that have maximum variation (see Asmussen and Creswell 1995) that emerged within our respective perspectives as members of TWG7. We collaboratively embraced connected learning in regard to peer culture, interests, and academic content from a range of perspectives (people, space, resources) to elucidate the nature of connected interactions that are dynamically expanding what we consider as 'learning'. In this paper we explore three concepts through illustrations of complex interactions and relationships, these include: (1) an open and bounded context (2) prescribed and emergent curriculum and (3) rise of a new class of influencer.

To begin, this short vignette about Peter illustrates some aspects of connected learning:

Peter loves music and is rarely seen without earbuds as he listens to his carefully curated, often eclectic playlists. He also cycles through playlists he has gathered from family and friends throughout the day. From an early age, Peter picked up song lyrics and melodies easily, and enjoyed singing at home and in the car. His mother took Peter and his brother to music lessons twice a week and made him practice piano every day, which was a chore (for Peter, brother and mother). His father, a musician, had a range of musical instruments at home for the boys to play. Father taught both Peter and his brother how to drum on professional kits and sing using gig microphones. However, when Peter was in early elementary school, his father, also a talented songwriter, gave him a small blue guitar and taught him how to strum a few notes. Peter took an early interest and carried the little guitar around the house and practiced placing his fingers to make different notes. While he often had to be forced to practice piano, Peter willingly spent hours playing guitar in his room, watching expert guitar players and tutorials on YouTube, listening to and singing along with his father and his band, and gradually learning to play his favourite guitar riffs. $\mathrm{He}$ used the internet to teach himself about guitars, both acoustic and electric, and to 
learn how to play music. He spent hours practicing on the guitar, and only 15 minutes per day, if that, on his brass band instrument. His band teacher was not amused. His father coached Peter in guitar basics, tuning, and tools, often took him and his brother along to open jams with other working musicians, and always played a range of music in the house and car. A rare highlight of Peter's school band experience was when Peter and his friend were granted the opportunity to play their electric guitars for the spring concert instead of their assigned instrument. Thank you, band teacher! Father continued to mentor Peter, who wanted to play some of his favourite rock ballads, as well as learn all of his dad's original songs on guitar. As he transitioned into high school, Peter's parents took him to an open mic jam session in the community. Despite some trepidation, Peter got up in front of dozens of community members and other musicians, and played three songs on his guitar in public. His dad recently took Peter to audition with a professional musician as part of the interview for a parttime job as a guitar tutor. Peter currently plays dozens of songs, including many of his father's tunes, and also creates his own music on guitar. He is currently scouting opportunities to play guitar in coffee shops.

Building upon Ito's (2013) description, connected learning is realized in this vignette of a young boy's personal interest in learning to play guitar, and pursuing his passion with the support of friends and caring adults, and with support of knowledgeable others in the connected internet community, and in turn, has been able to link this learning and interest to academic achievement in school, potential employment as a tutor, and civic engagement by playing in coffee shops and at open jams. This vignette provides narrative evidence of resilient, adaptive, and effective learning that leverages an individual interest as well as social, cultural and digital network support to overcome adversity and provide recognition.

\section{Concept 1: an open and bounded context}

The open and bounded context refers to learning environments, often mediated by digital technologies, that facilitate connected learning experiences. Open and bounded contexts are more often considered antithetically. In connected learning,'open' needs to be considered as open for connections to other learners, to experts, to online or physical resources while 'bounded' needs to be considered as bounded by personal interest, needs or topic. Learning environments are constructed in the form of platforms, tools and digital spaces. It is widely acknowledged that platforms and digital tools preposition certain kinds of contexts for engagement and therefore come to play a seminal role in the way technology enabled learning experiences are shaped (Amiel and Reeves 2008; Papert 1987; Wang and Hannafin 2005). In this section we consider this context in relation to two key aspects of connected learning namely-design and agency.

Firstly, in the field of learning sciences design refers to the underlying schemata that governs how a system would work which includes, but is not limited to, theoretical underpinnings, philosophical assumptions and contextual conjectures (Barab and Squire 2004; Collins 1996; Dorst 2011). The aspects of design play an affective role in the kind of learning and pedagogy engendered in and through such platforms and tools (Mulla et al. 2019). That is, connected learning is not an ingrained trait but a thoughtful construct of digital learning environments. The design for connected learning is usually underpinned by notions of interaction, collaboration and self-generating opportunities in which learning 
is actioned by participation and contributions which stimulate response-based interplays rather than receivership of content.

Secondly, in digitally enabled connected learning spaces, agency becomes an important characteristic. Passey et al. (2018, p. 426) define digital agency as an "individual's ability to control and adapt to a digital world" with agency demonstrating a felicity in terms of competence, confidence, autonomy and accountability with respect to the context. This notion of learner agency is perhaps relatable to Seymour Papert's active learner who, in a microworld while playing with tools, incubates ideas, owns the dynamics of space and constructs knowledge (Papert 1980). Cultivating such an empowered agency is a powerful idea which bears implications for learners and learning. Finally, in order to ensure that connected learning opportunities can be leveraged by all learners (to the extent possible) including those on the disability spectrum, the platforms and tools must be inclusive and adopt a universal design for learning (UDL). Accessible design and agency based practices have enormous potential to bridge the multidimensional educational divide (Alemán de la Garza et.al. 2019).

Digital platforms such as Moodle and Aula (see Aula education) both provide an online environment that integrates a learning management system with social media; on the other hand, CLIxPlatform (a next generation digital learning environment, NGDLE) embodies the constructionist principle by design for interactivity, creation and collaboration (CLIx 2018). These features are markedly different than many, popular, consumption modelled, platforms/LMSes (learning management systems) in the EdTech market which generally focus on audio/visual and tutorial based transmission/broadcasting pedagogy in closed platforms.

Learning environments that are designed for connectivity not only pave the way for pedagogical affordances that engender novel ways of learning but foreground implications and unique shifts in agency and identity of both learners and teachers/instructors. Participatory pedagogies (Veletsianos et al. 2013) orchestrate connected learning within environments designed on constructionist principles leading to active learning through interactions and collaboration. Moreover, newer ways of learning by way of civilised discourse and peer review have become essential twenty-first century skills. A recently released global literature review (Alemán de la Garza et.al. 2019) identifies eight key affordances that digital educational environments can offer when designed meaningfully, which includes active knowledge making and collaborative intelligence. Therefore, one could perhaps argue that one of the most significant constituents (and implications, because of a dialectical relationship) of connected learning is the change that takes place in an individual's agency aspects-both for learners and for teachers. And, such exercise of agency is consequential to and dependent on the extent of open-ness and bounded-ness of the design of a connected learning environment. In the subsequent paragraphs we explicate further on these ideas.

Further insight can be gained by examining a MOOC from the University of Calgary in relation to an open and bounded context, design and agency. The quality graduate supervision (QGS) MOOC, first piloted with 24 participants (Alharbi and Jacobsen 2018, 2016) and then with 107 participants in 2020, is a flexible, accessible and self-directed design for active online learning. This MOOC is underpinned by a connected learning design in which faculty from across disciplines engage in a series of prepared tasks and activities and contribute ideas and expertise to collaborative, yet self-directed, networked learning experiences, and in turn, incubate ideas, construct and share knowledge, and own the dynamics of the space. The theoretical framework (Alharbi and Jacobsen 2017) emerges from constructivism (Duffy and Cunningham 1996), connectivism (Siemens 2006) and learning communities (Lave and Wenger 1991,1998). Principles of connectivism (Siemens 2017) 
incorporated using an iterative design based research approach (Jacobsen 2014; McKenney and Reeves 2019) to the development and evaluation of the QGS MOOC include: learning and knowledge emerges from a diversity of experiences; learning is a process of connecting specialized nodes or information sources; nurturing and maintaining connections facilitates continual learning; ability to see connections between fields, ideas, and concepts is a core skill; currency (accurate, up-to-date knowledge) is the intent of all connectivist learning activities; and decision-making is itself a learning process.

In an intentional design to promote agency, oriented by connectivist learning theory, the QGS MOOC demonstrates three of four MOOC characteristics, adapted from Bates (2019) and originally described by Downes (2014): (1) autonomy of the learner (faculty participate when and where, learning is personal, accountability) (2) diversity of tools, learners, and knowledge (multimedia, multiple disciplines, diverse and emerging content) and (3) interactivity (cooperative learning, open and ongoing communication between learners, emergent knowledge). The fourth characteristic, openness, was demonstrated within the course through connections to other learners, to experts, to online resources, to activities, but not beyond the MOOC through unrestricted enrolment. Each of Downes (2014) three characteristics of a MOOC are elaborated upon with regards to connected learning in subsequent sections.

In drawing together the ideas within the cases of digital platforms and MOOCs, connected learning can be propositioned by a certain kind of context in which designs for agency explicitly advantage interactivity and co-creation of knowledge over content consumption. Therefore, an open and bounded context does play a significant role in constraining and or leveraging an individual's connected learning experiences that are rich and meaningful.

\section{Concept 2: prescribed and emergent curriculum}

As connected learning is internationalised, it is important to reflect on the meaning of curriculum globally. While several actions have been taken to evaluate new connected learning possibilities, formal or prescribed curriculum is currently constrained by context (Volungevičienė et al. 2020), and the values, content and aims of an institution (Williamson 2013). According to Williams, Karousou and Mckness (2011) curriculum can be either institutionally developed in a traditional way (prescribed) or negotiated with students inside a course, which is more contextual and open (emergent). An emergent curriculum can be considered as a non-formal framework, that does not arise from the prescribed curriculum but rather derives from institutional or social practices within connected learning processes.

An emergent curriculum arises from the openness, interaction, and self-organization at scale of the information and knowledge production in social networks, which can generate an exponential growth of emerging learning modalities. Students can organize, co-design and determine both the process and the final application of learning, but both have been found to be unpredictable in dynamic and complex contexts (Gallagher and Wessels 2011; Jahnke et al. 2020). Emergent curriculum is developed as students and instructors collaborate and share questions, problems and particular interests (Wein 2014). Aligned with this perspective, Bell et al. (2016) claimed that 'community is the curriculum' with Bates (2019) confirming this statement by including online courses and connected activities as the perfect way to unite people from around the world on a common interest. However, 
there has been some debate about the alignment of an emergent curriculum with connected learning (see Cox 2005) requiring several discussions and definitions regarding the growth of virtual communities and networks. Nevertheless, there were still concerns such as those expressed by Waters (2015) who claimed the lack of academic rigor and establishment of an emergent curriculum may be perceived as academically fragile.

The current digital era is characterized by the plasticity of information, the perpetual beta, an open, decentralized approach to information, and open-source politics, all powered by the internet's forces (Pinar 2012). Williamson (2013) suggested that the curriculum of the future is socially shaped and includes: networked and connected learning, psychological competence in inquiry and creativity; and the ability to make one's own projects as a lifelong endeavour. In open and distant learning, there has been an increase in the production of learning objects (LO) and open educational resources (OER). LO are digital online content that come in a variety of media types: texts, videos, audios, images, graphics, computerized simulations, in large and small sizes. When ready to be disseminated on the web, they are encased in open educational resources (OER), as a kind of 'protective travelling box' containing metadata which permits cataloguing of content. In simple terms, there can be many LO in an OER.

LOs and OERs are considered valuable elements of an emergent curriculum, representing the new 'bricks' which allow learners to construct their own individual knowledgebases (Gill 2019). Further insight can be gained by examining OERs evident in curriculum development projects in Norway and Canada. The Norwegian Digital Learning Arena (NDLA) was a project, initiated in 2007, aimed at collaboratively designing and disseminating free and open educational resources of good quality that targeted various subjects taught at the secondary level. The objective of this initiative was to contribute to the development of a culture of sharing within upper secondary education in Norway. In her thesis work on the exchange of educational resources in secondary education in Vietnam, Thai N'Guyen documented the factors that favour and hinder the sharing of digital resources among teachers: (1) lack of confidence in production of LO and OER (2) Lack of time and competency (3) knowledge of copyright and recognition issues and, (4) lack of culture of sharing, due to competition between teachers (Nguyen and Bruillard 2011). Also explored were the factors that promoted connected learning incentives, such as access to quality easy-to-use resources and trust in group discussion (Nguyen and Bruillard 2011). There are many aspects to connected learning though OERs.

In Quebec, Canada, remote networked schools (RNS) is an education ministerial initiative which uses information and communication technologies (ICT) for enriching the learning environment of small geographic isolation K-12 rural schools. These schools frequently encountered challenges such as a lack of specialized resources for students, multi-grade classrooms, small numbers of registered students and professional isolation (Turcotte 2008). In 2016, 250 schools located in 31 school districts were given access to OERs as well as videoconferencing tools and discussion forums (Laferrière et al. 2016). Across schools, class activities included discussion forums using peer-to-peer exercises on a routine basis (Laferrière et al. 2016) in order to foster a student-centred learning environment for collaborative knowledge-building (Bereiter and Scardamalia 2010). RNS class discourses revolved around students' interests and putting their ideas into a process of codevelopment (peer-supported) for the production of an artefact (Laferrière 2005). The collective discourse was guided, on the one hand, by teachers who strategically scaffolded learners' collaboration (emergent curriculum) accordingly, to the educational aims (formal curriculum), and, on the other hand, by students who were engaged in understanding deep disciplinary content (Turcotte 2008). RNS created a connected learning community in an 
openly networked environment which was peer-supported, interest-powered, academically oriented and teacher facilitated.

The creation and use of OERs can represent both the formal and emergent curriculum, in a singular Learning Object or through collective use of resources bounded together for a purpose. Both formal (academic) and emergent (learning processes and protocols) curricula are part of connected learning. Blessinger and Bliss (2016) make an important point, by proposing that OER should be well designed and enable any user (at targeted level) to engage with it, incorporating aspects that support agency and self-regulation. This premise supports Kim et al. (2015) claim that OERs can function to support users in managing their learning smoothly which is a more important consideration than the quality of the resource. These ideas align with the focus on an emergent curriculum which considers online users' needs, interests, interactions and learning processes with the co-creation of content. Above all, the move to the increase use of OERs in open learning stems from the basic premise of a democratised education with OERs being part of a social and inclusive agenda for distribution and access to learning opportunities (Halder 2019). McEneaney (2015) helps to extend this bridging view on connected learning by contending that "in recognition of the existence, elaboration and wide accessibility of the Internet, curricula need to differentiate between comprehension and familiarity, with teacher-led support for querying and expert curation of virtual spaces as the surest connection to specialist communities and powerful knowledge for the next generation of learners" (p. 817). Connected learning and co-design of OERs is a strategy that links what is learning in formal schooling with informal learning outside of school (Erstad and Voogt 2018).

\section{Concept 3: rise of a new class of influencer}

Learning online is increasing with people shifting to connect, share ideas, collaborate and expand their learning opportunities more easily and flexibly. Educators are no exception. Educators' use of social networks to connect and learn has been linked to overcoming isolation, addressing the lack of collaboration between teachers (Flinders 1998) and countering the irrelevancy of school-based training and professional development (Prestridge and Main 2018). Research related to educators' connected learning activity through a single digital space, such as Twitter, Pinterest, Reddit, Facebook, and Edmodo indicate that teachers often turn to digital settings to augment their professional development due to the irrelevance of what is offered at the school site (Hood 2017; Prestridge 2019). There are also social and psychological benefits from connecting, communicating, and collaborating online, such as gaining access to social and emotional support (Carpenter and Krutka 2014; Hur and Brush 2009; Seo 2014); expanding learning opportunities beyond their local contacts, (Manca and Ranieri 2017; Schlager et al. 2009); and overcoming social isolation (Trust et al. 2016). What is new and interesting is the shift in who are considered the experts or influencers in these connected spaces. In social media an influencer is a person, no matter what age or type of credentials, who for the purpose of persuasion builds a dialogue on specific topics related to their expertise and in doing so builds up a following of interested people wanting to extend their knowledge and experience in the same area (Lin et al. 2019). Folfvord et al. (2019) contend that 'influencers' have an impact on learning and cognitive behaviours of others by modelling and reinforcing ideas through online interactions. 
The influence of influencers can be evidenced within online professional learning networks (PLNs) established within organised coursework or established by an individual. A PLN has been described by Trust (2012) as a "system of interpersonal connections and resources" that can be used for informal learning, collaboration, and exchanging knowledge and ideas (p. 133). Research has shown that influencers in these networks are those who go beyond self-seeking behaviours by contributing ideas to help and extend the understanding of others as well as to build the collective (see Prestridge 2019; Trust and Prestridge 2021). In other words, they seek to influence others. The impact of the Influencer needs to be considered in regard to the participant, as by nature, connected learning is driven be selfinterest and needs. The emergence of one's PLNs to support connected learning in both formal and informal learning spaces will now be illustrated.

In India, an online certificate course called Reflective Teaching with ICT, designed for government rural teachers, created multiple PLNs that connected teachers across districts to share their learning and practice on Telegram and Whatsapp platforms. These PLNs not only supported teachers in completing their blended courses, the PLNs also enabled teachers to stay connected and upgrade their professional development with the support of peers and course facilitators (both could be considered influencers). Whatsapp data from the teachers who took the course within the Integrated approach to technology in education (ITE) initiative revealed that the participation in these PLNs increased around face to face events and visits related to the initiative in their schools and districts (Paltiwale et al.2020). A similar surge has been observed in the lockdown period during the COVID19 pandemic, where participation in these PLNs increased around virtual ITE webinars and quizzes for the teachers and students and when teachers shared their experiences of conducting online classes with each other.

In Mexico, MOOC production is relatively recent, even though there have been efforts to promote open and social spaces for learning (see Zubieta and Rama 2015). The digital knowledge for teachers initiative was one of the successful efforts in which more than 8000 teachers participated with very good results in terms of achievement and used peer and self-evaluation (Mercado-del-Collado et al. 2019). The notion of "digital knowledge" referred to a graduated structure of technological knowledge and skills that educational actors developed and possessed regarding ICT (Ramírez et al. 2018).

These two cases illustrate organised or institutionally structured online learning that is based on connections. As a construct, organised PLNs can be represented in various forms (see Lantz-Andersson et al. 2018). A contrasting analysis of 52 studies of formal and informal online teacher communities conducted by Lantz-Andersson et al. (2018, p. 33) shows that "while formally-organized and informally-developed communities address different needs among teachers and support different outcomes, they also share several common characteristics. Indeed, regardless of type, online communities can be a valuable means of developing supportive and collegial professional practices". Bonilla and Rodríguez (in press) identify four types of educational web portals: institutional portals set up by an educational administration; teacher networks portals which contain materials elaborated by teachers and managed by different agents; portals not designed for formal education mastered by different agents; and commercial platforms operated by a publishing company. Access to the resources produced can be completely open, especially in the case of institutional portals and educational portals that do not necessarily concern formal education. A question that remains is do these varied types of connected learning portals influence the kind of influencer, and or does a PLN represent the influence of an influencer?

Formally-organized and informally-developed learning communities are emerging. However, a consideration of PLNs that are more organic, needs based or as represented 
from an individual's perspective is also necessary to increase our understanding of connected learning. As connected learners, educators can cultivate a network of individuals who support and extend their learning, participate in spaces that grow their thinking, and use tools to access and curate new information; Teachers can improve their teaching and student learning, expand their social support, build confidence in their practice, and shift their identity to a teacher-learner or teacher-leader (Trust 2016). As educators construct and share knowledge and support one another in online settings, they engage in a variety of actions ranging from reading, writing, and responding to posts to leading conversations to reciprocal mentoring. An analysis of expert teachers' actions in online spaces (Prestridge 2019) resulted in the development of the following four categories of engagement: infoconsumer (reading all posts), info-networker (reading and sharing posts), self-seeking contributor (posting or responding to posts when there is a self-determined need, such as getting feedback or help), and vocationalist (posting or responding to posts to contribute to the network and build the profession). The diversity of these categorizations showcase that educators' actions in digital settings vary in unique ways as current research tries to make them understood.

Connected learning can be represented through formally-organized and informallydeveloped institutionally based networks as well as though more organic, self-driven networks. There is currently more understanding in the literature around why and how educators are engaging in PLNs than there is about the notion of influencing action on learning through these networks. PLNs operate on a distributed learning approach rather than on an instructor centric model. As such, further investigation is needed to realise the characteristics of influencers in these spaces with regard to the actions of an individual and or the needs of the individual.

\section{Framing the complexities of conceptualised connected learning}

Overall the field of research on connected learning currently lacks the complexity needed to understand how and why learning happens within a multifaceted network of people, spaces, and tools. The three concepts presented here begin to unpack new ways of thinking about the more common 'face to face' notions of what represents learning. The three concepts of an open and bounded context; emergent and prescribed curriculum; and the rise of the Influencer, have many common elements that begin to unpack the nature of learning. These common elements will be discussed here to begin to represent the complexities of connected learning: (1) autonomy of the learner (2) diversity of tools, learners, and knowledge and (3) Issues of time. A model will be presented to contribute to the complexities of this emerging phenomenon.

\section{Autonomy of action}

Extending upon Siemens' (2017) description of an individual learner as a network, the learners' knowledge can comprise their own personal network of ideas, observations, experiences, and insights within a network of learners where each individual learning activity is considered in relation to others. An individual's learning is expected to feed into the organizations of which the individual is a part, in relation to the many organisations that the learner exists within. Siemens' (2017) description of the cycle of knowledge development (personal learning to network to organization) in connectivism is drawn upon as 
a design principle to help us understand connected learning. One's own knowledge and that of others does not result from the transmission of information from an expert to novices, but from the sharing and flow of knowledge between participants (Bates 2019). For example, in the QGS MOOC (Alharbi and Jacobsen 2018) academic faculty learners draw upon their own experiences of being supervised as well as ideas and outcomes from their experience supervising graduate students in sharing insights and making knowledge contributions to the learning community within the MOOC; enhanced collective knowledge building of effective supervision practice contributes to increased organizational capacity for higher quality graduate supervision.

\section{Diversity of tools, people, and knowledges}

Connected learning can be conceived organisationally for many as a formal or informal system and or by self through a personalised system. With either lens, connected learning is a uniquely cultivated system of people, spaces, and tools that assist the improvement of a skill, knowledge and or process. When educators or graduate supervisors cultivate a network of individuals who support and extend their learning, participate in spaces that grow their thinking, and use tools to access and curate new information, they can improve their affective, cognitive, identity, and social growth capabilities (Trust 2016). The diversity of tools, learners and knowledge can be considered as unlimited and in direct relation to the individual. This points to the multifaceted, dynamic nature of connected learning, in which participants can interact with people, spaces, and tools in multiple ways.

\section{Time}

Anytime, available time or investment in time is a common thread throughout participants' engagement in connected learning. Educators must carve time out from their own personal schedules to participate in formal and self-directed learning in digital spaces. As opposed to in-person organised onsite settings, time must be allocated to participating in online spaces; time in figuring out how to make use of the tool features; time to interact with others in meaningful ways, and time to sort through the information that is available (Trust and Prestridge 2021). Connected learning via the MOOC for faculty development optimizes participation by leveraging the temporal and spatial flexibility of anytime, anywhere individual/community learning spaces in-between demanding research, teaching and service commitments (Alharbi and Jacobsen 2019). In many research projects spanning the last 30 years there has been consistent examination of the effect of time on the use of technologies in learning (López-Pérez et al. 2019; Soules and Adams 1998). Emerging ideas that are pivotal to connected learning are spending too much time online with connecting learning being considered a time sink (Trust and Prestridge 2021).

\section{Model of connected learning}

The three elements presented above have been diagrammed to illustrate their relationships within connected learning. Connected learning encompasses an individual's autonomy of action for learning with tools, people and knowledges underpinned by their use of time. Action with the choice of tool, the choice of user and the choice of knowledge is dependent on personalised time which is multifaceted, dynamic and relative to the self. As such 
connected learning, even though it is conceivable by networked, it is represented as individually orchestrated. (see Fig. 1).

Building on the introductory vignette about Peter learning guitar, we elaborate further using the model of connected learning. The 'Learners' in this model are the central focal point rather than the Instructor, Institution or disciplinary knowledge. Peter accessed people and resources, both digital and physical, in his network to pursue his personal and passionate interest in learning how to play the guitar. The learner has autonomy of action for interaction with a diverse range of tools, knowledges and people in relation to conceptions of time. Driven by his own interest, Peter often lost track of time in his pursuit of new songs and knowledge about guitars, interactions with online mentors, and practicing and honing his skills. Context does not necessarily matter as bounded by location (local or global) through social media, in online coursework or in more traditional modes of face to face interaction. Peter is able to access informal and asynchronous online mentors and multimedia resources, often with/from his favourite musicians, as often as he likes to continue learning how to improve as a musician. Connected learning by the individual is influenced by many elements such as motivation, recognition, trust, opportunities, learning approach/ continuum/ preference, resources and the expert (if present) in the connected context. Each element has possible parameters which therefore influence the dynamics of temporal interactions.

\section{Major consideration with moving forward}

The rhetoric for learning has typically focused on canonized formal institutional content acquisition with reference to discipline specific knowledge gains. In reinforcing the developing conceptualisation of connected learning, stronger notions are forming about an

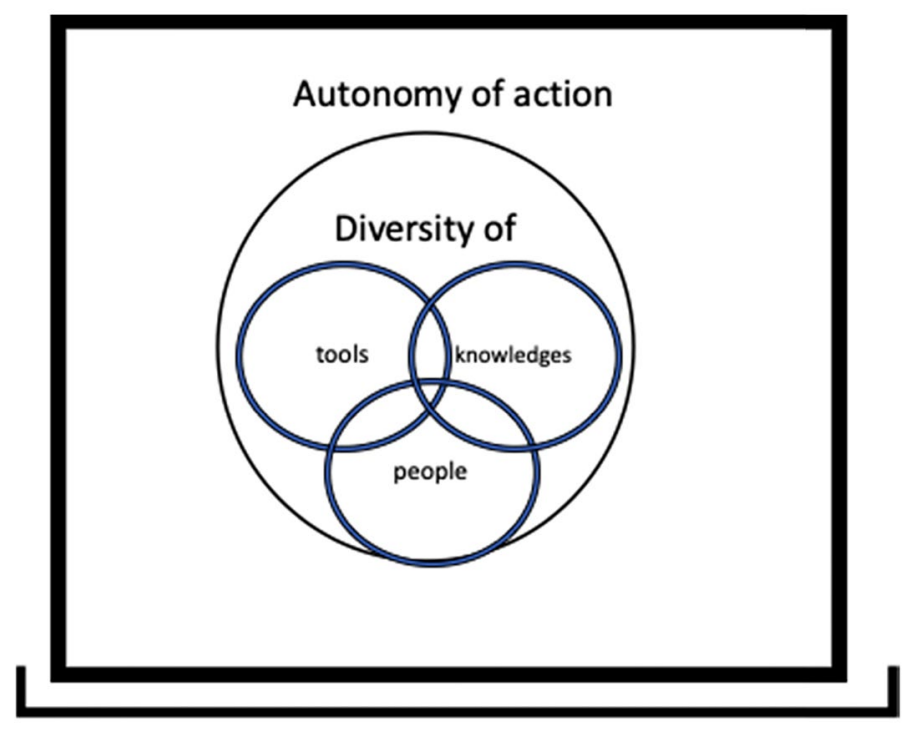

Time

Fig. 1 Model of connected learning 
individual's self-directed activity that is chosen within a quasi-environment that may be 'created' but the learning connections are self-generated. In describing this in another way, it is possible to conceive of an educational centre which offers a refreshing new model based on an idea in communications: a "pulling effort" on the part of the learner rather than the "pushing effort" on the part of the institution. In high school students, for example, the spontaneous creation of private ways to communicate through social media is common: Facebook groups, Messenger groups, Snapchat, Instagram or other interfaces, with none of them dedicated to learning. Whereas, more formal school-based discussion forums are the favourite web application for students to ask questions to their peers about homework. In this paper we are suggesting the need to be moving towards considering learning as 'mashups' of discipline knowledge with personal interests, experiences and expertise shaped by a multitude of choices as learning paradigms. Considering the abundance of information suitable for learning available on the web today, our first principle is to encourage individuals new to digital technology to seek out subjects, topics, questions, problems which are of strong personal interest and which provide ample continuing motivation for study. Perhaps a brief and adequately succinct definition for Connected Learning which is that found in Educause's Learning Initiative: “...how to use connections to find answers, seek out mentors and experts, investigate procedures, experiment with possibilities, and develop competencies." We have only just begun to put these elements (tools, people and knowledges) into some type of inter-relationship and ask the research community to examine each of these concepts to expand, identify relationships and further depth to this fascinating and critically-important new learning paradigm of connected learning.

Acknowledgements We would like to acknowledge all members of the TWG7: Connected Learning that were not able to contribute to this paper but were the founding members of a team that came together to examine a very new concept from multiple perspectives. The basis of our discussions have informed this paper. With thanks to: Éric Bruillard; Fredric Litto; Clare Brett; David M. Smith; Yoko Mochizuki; Sonia Huguenin; Vincent Faillet; Pier-Luc Jolicoeur; Mar Mbodj. Until we meet again to develop these ideas further.

\section{Compliance with ethical standards}

Conflict of interest There is no conflict of interest.

Ethical approval This research is compliant with Ethical Standards for human participants including informed consent.

\section{References}

Alemán de la Garza, L., Anichini, A., Antal, P., Beaune, A., Crompton, H., \& Tsinakos, A. (2019). Rethinking pedagogy: Exploring the potential of digital technology in achieving quality education.

Alharbi, H., \& Jacobsen, M. (2019). The design and evaluation of a miniMOOC for quality graduate supervision in higher education. American Educational Research Association (AERA), Toronto, April 5-9, 2019.

Alharbi, H., \& Jacobsen, M. (2018). Evaluating the design and development of the quality graduate supervision miniMOOC. Quarterly Review of Distance Education, 19(1), 13-26.

Alharbi, H. \& Jacobsen, M. (2017). The implementation and evaluation of a quality graduate supervision miniMOOC. In J. Dron \& S. Mishra (Eds.), Proceedings of E-Learn: World Conference on E-Learning in Corporate, Government, Healthcare, and Higher Education (pp. 531-536). Vancouver, British Columbia, Canada: Association for the Advancement of Computing in Education (AACE). Retrieved October 30, 2017 from https://www.learntechlib.org/p/181228/. 
Alharbi, H., \& Jacobsen, M. (2016). Educational development for quality graduate supervision. Papers on Postsecondary Learning and Teaching, 1(1), 41-46.

Asmussen, K., \& Creswell, J. (1995). Campus response to a student gunman. Journal of Higher Education, $66(5), 575-659$.

Amiel, T., \& Reeves, T. (2008). Design-based research and educational technology: Rethinking technology and the research agenda. Journal of Educational Technology \& Society, 11(4), 29-40.

Barab, S., \& Squire, K. (2004). Design-based research: Putting a stake in the ground. Journal of the Learning Sciences, 13(1), 1-14.

Bates, A. W. (2019). Teaching in a digital age, 2nd Edition. Retrieved from https://opentextbc.ca/teachingin adigitalage/.

Bell, F., Mackness, J., \& Funes, M. (2016). Participant association and emergent curriculum in a MOOC: Can the community be the curriculum? Research in Learning Technology. https://doi.org/10.3402/rlt. v24.29927.

Bereiter, C., \& Scardamalia, M. (2010). Can children really create knowledge? Canadian Journal of Learning and Technology, 36(1), 1-24.

Blessinger, P., \& Bliss, T. J. (2016). Open education: International perspectives in higher education. Cambridge: Open Book Publishers.

Carpenter, J. P., \& Krutka, D. G. (2014). How and why educators use Twitter: A survey of the field. Journal of Research on Technology in Education, 46(4), 414-434.

Collins, A. (1996). Design issues for learning environments. In S. Vosniadou, E. De Corte, R. Glaser, \& H. Mandl (Eds.), International perspectives on the design of technology-supported learning environments (pp. 347-361). Mahwah, NJ: Lawrence Erlbaum.

Cox, A. (2005). What are communities of practice? A comparative review of four seminal works. Journal of Information Science, 31(6), 527-540.

CLIx. (2018). Connected Learning Initiative 2015-2018. Mumbai. Retrieved from https://clix.tiss.edu/wpcontent/uploads/2018/08/CLIx-Handbook-English.pdf.

Downes, S. (2014). The MOOC of one. Valencia, Spain: Keynote Talk at the International Academy of Technology Education and Development (IATED).

Dorst, K. (2011). The core of design thinking and its application. Design Studies, 32(6), 521-532.

Duffy, T., \& Cunningham, D. (1996). Constructivism: Implications for the design and delivery of instruction. In D. H. Jonassen (Ed.), Handbook of research for educational communications and technology (pp. 170-198). New York: Simon and Schuster.

Erstad, O., \& Voogt, J. (2018). The twenty-first century curriculum: issues and challenges (pp. 19-36). New York: Springer International Handbooks of Education.

Flinders, D. (1998). Teacher isolation and the new reforms. Journal of Curriculum and Supervision, 4(1), $17-29$.

Gallagher, K., \& Wessels, A. (2011). Emergent pedagogy and affect in collaborative research: A methopedagogical paradigm. Pedagogy, Culture \& Society, 19(2), 239-258.

Gill, D. (2019). But i don't use a textbook: Open educational resources for all.

Halder, D. (2019). Potentials of unencumbered OER on lifelong learning: A critical review.

Hood, N. (2017). Conceptualising online knowledge sharing: What teachers' perceptions can tell us. Technology, Pedagogy and Education, 26(5), 573-585.

Hur, J. W., \& Brush, T. A. (2009). Teacher participation in online communities: Why do teachers want to participate in self-generated online communities of K-12 teachers? Journal of Research on Technology in Education, 41(3), 279-303.

Ito, M., Gutierrez, K., Livingstone, S., Penuel, B., Rhodes, J., Salen, K., et al. (2013). Connected learning: an agenda for research and design (p. 4). Irvine USA: Digital Media and Learning Research Hub.

Jacobsen, M. (2014). Design based research: Sponsoring innovation in education. Education Canada, 54(5), 22-24.

Jahnke, I., Meinke-Kroll, M., Todd, M., \& Nolte, A. (2020). Exploring artifact-generated learning with digital technologies: Advancing active learning with co-design in higher education across disciplines. Technology, Knowledge and Learning. https://doi.org/10.1007/s10758-020-09473-3.

Kim, B. W., Lee, W. G., Lee, B. R., \& Shon, J. G. (2015). Influencing factors in OER usage of adult learners in Korea. International Review of Research in Open and Distributed Learning, 16(2), 1-17.

Laferrière, T. (2005). Les communautésd'apprenants en réseau au bénéfice de l'éducation. Encounters on Education, 6, 5-21.

Laferrière, T., Métivier, J., Boutin, P.A., Racine, S., Perrault, C., Hamel, C., \& Breuleux, A. (2016). L'infrastructure d'orientation et de soutien de l'École en réseau : quatre cas d'illustration CEFRIO. 
Lantz-Andersson, A., Lundin, M., \& Selwyn, N. (2018). Twenty years of online teacher communities: A systematic review of formally-organized and informally-developed professional learning groups. Teaching and Teacher Education, 75, 302-315.

Lave, J. (1991). Situating learning in communities of practice. Perspectives on Socially Shared Cognition, 2, 63-82.

Lave, J., \& Wenger, E. (1998). Communities of practice: Learning, meaning, and identity. New York: Cambridge University Press.

Lin, M., Vijayalakshmi, A., \& Laczniak, R. (2019). Toward an understanding of parental views and actions on social media influencers targeted at adolescents: The roles of parents' social media use and empowerment. Frontiers in Psychology, 10, 2664.

López-Pérez, V., Ramírez-Correa, P., \& Grandón, E. (2019). Innovativeness and factors that affect the information technology adoption in the classroom by primary teachers in chile. Informatics in Education, 18(1), 165-181.

Manca, S., \& Ranieri, M. (2017). Implications of social network sites for teaching and learning where we are and where we want to go. Education and Information Technologies, 22(2), 605-622.

McKenney, S., \& Reeves, T. (2019). Conducting educational design research (2nd ed.). New York: Routledge.

Mercado Collado, R. J., Jácome Avila, N., Ortega Guerrero, J. C., Casillas Alvarado, M., \& RamírezMartinell, A. (2019). Patrones de participación y logro en un MOOC de SaberesDigitales para Docentes en servicio de México. Research in Education \& Learning Innovation Archives (REALIA), 23, 80.

Mulla, S., Shende, S., \& Nagarjuna, G. (2019). Including the excluded, connecting the disconnected: Lessons from a large scale experiment in India of designing open educational technologies that work for all Open Education Global Conference 2019 Open Education for an Open Future Milan: Open Education Consortium.

Nguyen, T \& Bruillard, E. (2011). Exchanging digital educational resources among teachers: A survey in Vietnam, SITE 2011, Nashville USA. Norwegian Digital Learning Arena (Nasjonal digital læringsarena) http://om.ndla.no/aboutndla. Subsidized by the counties (regions) and not by the State, NDLA is part of the Nordic network of open educational resources. Retrieved from https:// om.ndla.no/about-ndla/.

Paltiwale, S., Sarkar, D., \& Charania, A. (2020) Use of community of practice for in-service government teachers in professional development In Open Conference on Computers in Education. (pp. 73-77). Cham: Springer.

Papert, S. (1980). Mindstorms: Children, computers and powerful ideas. New York: Basic Books.

Papert, S. (1987). Information technology and education: Computer criticism vs technocentric thinking. Educational Researcher, 16(1), 22-30.

Passey, D., Shonfeld, M., Appleby, L., Judge, M., Saito, T., \& Smits, A. (2018). Digital agency: Empowering equity in and through education. Technology, Knowledge and Learning, 23(3), 425-439.

Pinar, W. (2012). What is curriculum theory? London: Routledge.

Prestridge, S. (2019). Categorising teachers' use of social media for their professional learning: A selfgenerating professional learning paradigm. Computers \& Education, 129, 143-158.

Prestridge, S., \& Main, K. (2018). Teachers as drivers of their professional learning through design teams, communities, and networks. In J. Voogt, G. Knezek, R. Christensen, \& K. W. Lai (Eds.), Handbook of information technology in primary and secondary education. Switzerland: Springer.

RamírezMartinell, A., Casillas Alvarado, M. Á., \& Aguirre González, I. R. (2018). Habilitacióntecnológica de profesoresuniversitarios y docentes de educaciónbásica. Apertura (Guadalajara, Jal.), 10(2), 124-139.

Schlager, M. S., Farooq, U., Fusco, J., Schank, P., \& Dwyer, N. (2009). Analyzing online teacher networks: Cyber networks require cyber research tools. Journal of Teacher Education, 60(1), 86-100.

Seo, K. (2014). Professional learning of observers, collaborators, and contributors in a teacher-created online community in Korea. Asia Pacific Journal of Education, 34(3), 337-350.

Siemens, G. (2006). Connectivism. Learning theory or pastime for the self amused?. Retrieved from http://www.elearnspace.org/Articles/connectivism_self-amused.htm.

Siemens, G. (2017). Connectivism: A learning theory for the digital age chapter 19. In West, R. E. (Ed.), Foundations of learning and instructional design technology. Press Books.

Soules, A., \& Adams, E. (1998). Classroom technology: A view from the trenches. Educom Review, $33(3), 50-53$.

Trust, T. (2012). Professional learning networks designed for teacher learning. Journal of Digital Learning in Teacher Education, 28(4), 133-138. 
Trust, T. (2016). New model of teacher learning in an online network. Journal of Research on Technology in Education, 48(4), 290-305.

Trust, T., Krutka, D. G., \& Carpenter, J. P. (2016). "Together we are better": Professional learning networks for teachers. Computers \& Education, 102, 15-34.

Trust, T., \& Prestridge, S. (2021). The interplay of five elements of influence on educators' PLN actions. Teaching and Teacher Education, 97, 103195.

Turcotte, S. (2008). Computer-supported collaborative inquiry in remote networked schools (pp. 1-231). Montreal: McGill University.

Veletsianos, G., Kimmons, R., \& French, K. (2013). Instructor experiences with a social networking site in a higher education setting: Expectations, frustrations, appropriations, and compartmentalization. Education Technology Research and Development, 61, 255-278.

Volungevičienè, A., Teresevičienè, M., \& Ehlers, U. (2020). When is open and online learning relevant for curriculum change in higher education? Digital and network society perspective. Electronic Journal of e-Learning, 18(1), 88-101.

Wang, F., \& Hannafin, M. (2005). Design-based research and technology-enhanced learning environments. Educational Technology Research and Development, 53(4), 5-23.

Wein, C. A. (2014). The power of emergent curriculum: Stories from early childhood settings. Washington DC: National Association for the Education of Young Children.

Williamson, B. (2013). The future of the curriculum: School knowledge in the digital age. Cambridge: The MIT Press.

Zubieta, J., \& Rama, C. (2015). The university at the technological forefront: Massive courses Open online (MOOC). Distance Education in Mexico A new reality University. Mexico: UNAM/Virtual Educa.

Publisher's Note Springer Nature remains neutral with regard to jurisdictional claims in published maps and institutional affiliations.

Sarah Prestridge research focuses on the nexus between digital pedagogy, online education and teacher professional development. In drawing these three areas together, my research has theorised how to change teacher instructional practices through triggers in professional inquiry which shift the ways teachers' teach in the classroom and online. This work provides strong foundations for on-going quality research and has been recognised internationally through multi-disciplinary research projects and partnerships, publications, writing collaboratives and keynotes.

Michele Jacobsen design-based and case study research focuses on K-12 and post-secondary learning and teaching with technology. Informed by the learning sciences, I study (i) how to facilitate active learning via the creation, design, use and evaluation of technological processes and systems, (ii) the innovations and changes required in education to sponsor deep learning with technology, and (iii) the shift from transmission to participatory, knowledge building learning cultures that sponsor intellectual engagement. Related research includes online / blended learning, graduate education, academic publishing, teacher professional learning, and ethics in online research.

Sadaqat Mulla leads the education technology group at Connected Learning Initiative (CLIx) and I teach ICTs \& New Media in Education for MA Education program at Centre for Education, Innovation \& Action Research, TISS, Mumbai. I have been working at the cross-section of Education, Technology and Development sector, in both formal and informal settings, for more than a decade and have been intimately involved in design, development and integration of ICTs and OER in school and higher education.

Sandra Gudiño Paredes Doctor of Educational Innovation by Tecnológico de Monterrey and passionate about Education, I am currently Director of postgraduate education in Humanities and Education in online format, where I greatly enjoy the interaction with our students, most of them inserted in the education sector of Mexico and Latin America. I really like research in Educational Innovation, Comparative Education and Projects that allow me to grow every day and contribute to our university being one of the best in the world.

Amina Charania has a doctoral degree from Iowa State University in Education. She initiated and led the initiative called Integrated approach to Technology in Education (ITE), at Tata Trusts. ITE offers a pedagogic framework for authentic and connected learning which is integrated with the curriculum. ITE currently caters to over 30 thousand students from socially marginalized pockets in India. She also leads the 
Teacher Professional Development cell of the Connected Learning Initiative at TISS, which is a joint project with MIT. Over the years, she has gathered first-hand experience from the rural middle and secondary schools. 